\title{
Avaliação preliminar da capacidade de carga de uma célula experimental de resíduos sólidos urbanos com base em ensaios de laboratório e campo
}

\section{Preliminary assessment of the load capacity of a waste urban solid experimental cell based on laboratory and field trials}

Data de entrada: 10/04/2015

Data de aprovação: $02 / 07 / 2015$

Andressa de Araujo Carneiro / Alfran Sampaio Moura

DOI 10.4322/dae.2015.006

\section{RESUMO}

Na presente pesquisa, estuda-se o comportamento geomecânico dos Resíduos Sólidos Urbanos (RSUs) provenientes do Aterro Sanitário Metropolitano Oeste de Caucaia (ASMOC), onde foram realizados ensaios no solo de cobertura e em uma célula experimental de RSU. Para a avaliação da capacidade de carga do aterro de RSU, realizaram-se, ainda, uma sondagem à percussão (SPT) e provas de carga direta. Após a análise dos resultados, avaliou-se o uso futuro da área em estudo como fundação de pequenas edificações, subleito de pequenas vias de acesso e área verde de parque recreativo. Com base nos resultados, pode-se afirmar que é possível o uso da área para essas finalidades, desde que os processos de biodegradação tenham sido cessados, os sistemas de drenagem de gases e de chorume estejam devidamente dimensionados e o solo de cobertura esteja adequadamente compactado.

Palavras-chave: Aterro sanitário. Comportamento geomecânico. Prova de carga direta.

\section{ABSTRACT}

In this research we study the geomechanical behaviour of urban solid waste from the Metropolitan West Caucaia landfill (ASMOC). To evaluate the capacity of the MSW landfill, it was also held a standard penetration test (SPT) and plate load tests. After analysing the results, we evaluated the future use of the study area for instance the foundation of small buildings, subgrade small access roads or green area of playgrounds. Based on the results, it can be stated that it is possible to use the area for those purposes, since biodegradation processes have been terminated, drainage systems of gas and leachate are rightly designed and that the soil surface is properly compacted.

Keywords: Landfill. Geomechanical behavior. Plate load test.

\section{Andressa de Araujo Carneiro}

Geóloga. Mestre em Engenharia Civil na área de Geotecnia pela Universidade Federal do Ceará. Professora no Departamento de Recursos Hídricos, Geotecnia e Saneamento Ambiental da Universidade Federal do Piauí.

\section{Alfran Sampaio Moura}

Engenheiro civil. Mestre e Doutor na área de Geotecnia pela Universidade de Brasília. Professor no Departamento de Engenharia Hidráulica e Ambiental da Universidade Federal do Ceará.

Endereço para correspondência:

Universidade Federal do Piauí - Campus Universitário Ministro Petrônio Portella

Campus Universitário Ministro Petrônio Portella, s/n - Bairro Ininga - 64049-550

Tel.: (86) 3237-1018

E-mail: andressa.deacagmail.com 


\section{INTRODUÇÃO}

Os aterros sanitários são considerados o método mais adequado de disposição final para os Resíduos Sólidos Urbanos (RSUs), por serem economicamente mais viáveis e ambientalmente mais seguros, devido ao fato de permitirem o tratamento dos líquidos e gases gerados pela decomposição dos resíduos, garantirem a proteção das águas superficiais e subsuperficiais, do solo, do ar e do próprio homem, além de apresentarem aspectos visuais menos impactantes se comparados a outros métodos de disposição.

Os RSUs são caracterizados por apresentar uma grande heterogeneidade dos seus constituintes. Na sua fase sólida, por exemplo, são constituídos por materiais inertes estáveis, com características semelhantes às de materiais geotécnicos convencionais.

Com a realização deste trabalho, pretende-se verificar a possibilidade do uso de uma área desativada de um aterro de RSU como suporte para fundações de pequenas edificações, subleito de pequenas estradas de acesso, área para recreação, área verde ou alguma pequena obra civil.

Entre as principais propriedades abordadas na literatura, que caracterizam os RSUs dispostos em aterros sanitários, destacam-se a composição, a distribuição do tamanho das partículas, o teor de umidade, a temperatura, a produção de chorume, a biodegradabilidade, a produção de gases, o peso específico in situ e a permeabilidade.

As principais propriedades mecânicas do RSU são a resistência ao cisalhamento e a compressibilidade, bastante influenciadas pela composição e estado de alteração do resíduo, bem como pelo comportamento mecânico individual de cada componente.

Os recalques dos maciços sanitários, quando comparados com os maciços de solos, são muito elevados. De acordo com Boscov (2008), nos aterros sanitários ocorrem mecanismos responsáveis pelos recalques, como solicitações mecânicas, carregamento e erosão interna, mudanças físico-químicas, biodegradação ou degradação causada por microrganismos, dissipação das pressões neutras de líquidos e gases, creep e interação dos mecanismos. Somente a solicitação mecânica e a dissipação das pressões neutras estão diretamente relacionadas ao carregamento imposto. Os demais dependem do ambiente no qual os resíduos se encontram e das transformações bioquímicas no interior do aterro.

Da mesma maneira que em solos, a resistência dos RSUs aparentemente aumenta com o incremento de tensão normal. No entanto, devido ao seu alto teor de matéria orgânica e à sua estrutura fibrosa, os resíduos sólidos se comportam mais como um solo orgânico fibroso do que simplesmente como solo. Em consequência disso, os fatores que devem afetar os parâmetros de resistência dos resíduos são os seguintes (GONZALEZ, 1995): teor de matéria orgânica e fibras, idade e grau de decomposição dos resíduos sólidos, época em que se construiu o aterro, esforço de compactação, composição e quantidade de solo de cobertura.

\section{METODOLOGIA}

A metodologia adotada para a realização da presente pesquisa tem como base a execução das seguintes etapas: escolha do local para execução do estudo, construção de uma célula experimental de RSU, coleta de amostras deformadas de solo do local de construção da célula e de RSU da cidade de Fortaleza, caracterização física dos solos e dos RSUs amostrados, realização de ensaios de campo, instalação e monitoramento de marcos superficiais, apresentação e análise dos resultados.

O local escolhido para a realização do estudo foi o Aterro Sanitário Metropolitano Oeste de Caucaia (ASMOC), cuja área total equivale a 123,20 ha, sendo 78,47 ha destinados à disposição de resíduos, 32,15 ha de área de preservação ambiental, 7,04 ha de fai- 
xa de preservação de contorno, 3,19 ha de sistema viário interno e 2,35 ha de administração, urbanização e estacionamento (SANTOS, 2012).

A escolha do ASMOC partiu da necessidade de utilizar um aterro ativo, de forma a facilitar a futura construção de uma célula experimental.

A área cedida pelo ASMOC, correspondente a 225 $\mathrm{m}^{2}$ (15 m x $15 \mathrm{~m}$ ), foi estabelecida de modo que possibilitasse a execução dos ensaios de emissão de gases e geomecânicos, além de não interferir na rotina operacional do aterro.

Para a construção da célula experimental, apresentada na Figura 1, optou-se pelo método da trincheira. A utilização desse método possibilitou um menor custo com a construção da célula e facilidade de operação.

Posteriormente à etapa de escavação, foi realizado o nivelamento do fundo da escavação com um trator de esteiras. Em paralelo, foi instalado um sistema de drenagem de líquidos composto por um dreno cego, que perfazia a parte inferior e o lado esquerdo da célula para análise de lixiviado, como também um dreno de gás central para análise de gases, que foi usado na pesquisa de Santos (2012).

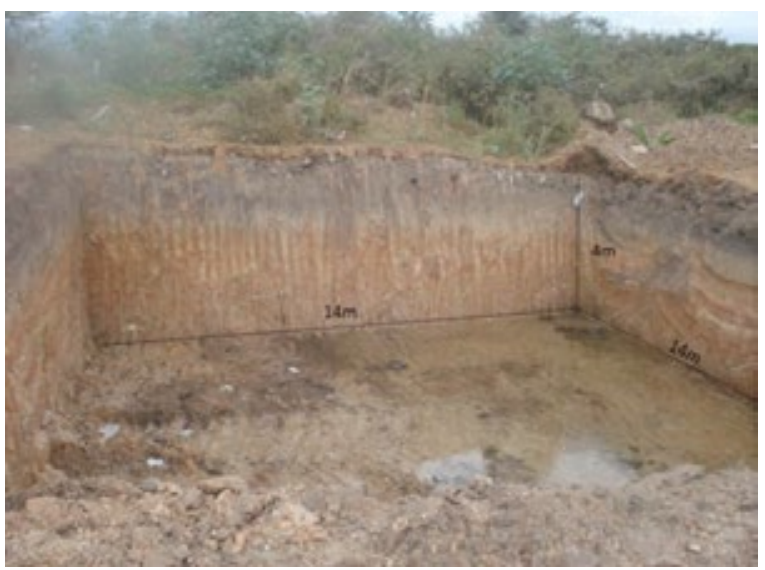

Figura 1 - Escavação executada para a construção da célula experimental na área do ASMOC.
As amostras de solo e de RSU foram coletadas com o auxílio de um trado concha e uma pá. Após a coleta, as amostras de solo e resíduo foram acondicionadas em sacos plásticos e encaminhadas para o Laboratório de Mecânica dos Solos e Pavimentação (LMSP) da Universidade Federal do Ceará (UFC).

Os ensaios de laboratório realizados no solo de cobertura da célula experimental foram: granulometria, densidade real dos grãos, limites de consistência, compactação e Índice de Suporte Califórnia (ISC).

Os resíduos do aterro da célula experimental foram caracterizados a partir da realização da composição gravimétrica, da determinação do teor de umidade e do peso específico realizado in situ.

Os ensaios de campo realizados foram a sondagem à percussão do tipo SPT e provas de carga direta, bem como o peso específico do solo de cobertura pelo método do frasco de areia e sua umidade natural, utilizando um speedy.

Com o objetivo de avaliar a evolução dos recalques na célula experimental ao longo do tempo, foi realizado um levantamento topográfico na área de estudo. Foram escolhidos aleatoriamente alguns pontos na área interna da célula experimental, cujas coordenadas foram obtidas com equipamentos topográficos de dupla frequência.

\section{RESULTADOS E DISCUSSÃO}

Foram coletadas duas amostras de solo de cobertura da célula experimental, nas profundidades de $20 \mathrm{~cm}$ (amostra 1) e $70 \mathrm{~cm}$ (amostra 2). Vale discutir que apenas a partir $75 \mathrm{~cm}$ de profundidade foi observada a presença de RSU no aterro sanitário.

A amostra 1 apresentou 11\% de pedregulho, 29\% de areia, $54 \%$ de silte e $6 \%$ de argila. Já a amostra 2 apresentou $6 \%$ de pedregulho, $33 \%$ de areia, $58 \%$ de silte e $3 \%$ de argila. De acordo com o Sistema de Classificação Unificado (SUCS), as duas amos- 
tras de solo correspondem ao tipo $\mathrm{CL}$, ou seja, argila de baixa compressibilidade. Pela classificação do Highway Research Board (HRB), as amostras de solo se enquadram no grupo $A-4$, equivalente a um solo siltoso.

O SUCS indica que, apesar da maior porcentagem da fração silte, as amostras foram classificadas como argila. Tal fato é atribuído à atividade da fração de argila contida nas amostras. Pela proposta de Skempton (1953), tanto a amostra 1 quanto a amostra 2 apresentam atividade superior a 1,25, correspondendo à argila ativa, o que explica seu comportamento de solo argiloso.

A densidade real dos grãos $\left(G_{s}\right)$ foi determinada pelo método do picnômetro, por meio da realização de três ensaios, em que foram obtidos resultados médios de 2,69. De acordo com Terzaghi e Peck (1967), valores típicos para os solos ficam em torno de 2,7; logo, os valores obtidos encontram-se na faixa de variação típica dos solos.

A curva de compactação do solo de cobertura da célula experimental indicou um peso específico aparente seco máximo $\left(\gamma_{\text {smax }}\right)$ de $18,4 \mathrm{kN} / \mathrm{m}^{3}$ e uma umidade ótima do solo $\left(w_{o t}\right)$ de 15,5\% para a energia do Proctor mormal.

Observa-se que o ISC da amostra de solo foi de $4 \%$ e a expansão, de 2,5\%. Pela norma do Departamento Nacional de Infraestrutura de Transportes (DNIT, 2009), observa-se que o solo ensaiado é adequado para execução do corpo de um aterro rodoviário, por possuir um ISC superior a $2 \%$ e uma expansão inferior a $4 \%$.

Na Tabela 1, é apresentada a composição gravimétrica do resíduo destinado à célula experimental do presente estudo. A amostra de resíduo indicou a presença predominante de matéria orgânica e, em menor quantidade, foram encontrados também borracha e alumínio. Esse resultado está coerente com outros trabalhos citados na litera- tura, que registram que no Brasil o componente de maior fração nos RSUs é a matéria orgânica.

Tabela 1 - Composição gravimétrica do resíduo destinado à célula experimental.

\begin{tabular}{|c|c|c|c|c|c|c|}
\hline \multirow{3}{*}{$\begin{array}{l}\text { Compo- } \\
\text { nentes }\end{array}$} & \multicolumn{6}{|c|}{ Composição gravimétrica } \\
\hline & \multicolumn{6}{|c|}{$\%$ em massa da amostra de 200 kg } \\
\hline & $\begin{array}{c}1^{\circ} \\
\text { ensaio }\end{array}$ & $\begin{array}{c}2^{\circ} \\
\text { ensaio }\end{array}$ & $\begin{array}{c}3^{\circ} \\
\text { ensaio }\end{array}$ & $\begin{array}{c}4^{\circ} \\
\text { ensaio }\end{array}$ & $\begin{array}{c}5^{\circ} \\
\text { ensaio }\end{array}$ & Média \\
\hline $\begin{array}{l}\text { Materiais } \\
\text { putrescíveis }\end{array}$ & 40,0 & 39,5 & 39,2 & 38,2 & 37,0 & 38,8 \\
\hline Outros & 11,1 & 12,3 & 12,0 & 13,3 & 14,5 & 12,6 \\
\hline Plástico & 15,1 & 16,4 & 15,2 & 15,7 & 15,6 & 15,6 \\
\hline Fralda & 8,7 & 7,9 & 8,5 & 8,1 & 8,8 & 8,4 \\
\hline Trapos & 8,3 & 7,6 & 7,4 & 8,2 & 6,9 & 7,7 \\
\hline Papel & 10,1 & 9,2 & 9,6 & 9,3 & 10,8 & 9,8 \\
\hline PET & 1,5 & 1,3 & 2,0 & 1,4 & 1,5 & 1,5 \\
\hline Vidro & 2,3 & 2,6 & 3,0 & 2,7 & 2,1 & 2,5 \\
\hline Ferro & 1,3 & 1,3 & 1,3 & 1,4 & 1,1 & 1,3 \\
\hline Borracha & 0.9 & 1,3 & 1,2 & 1,0 & 1,0 & 1,1 \\
\hline Alumínio & 0,7 & 0,7 & 0,7 & 0,9 & 1,0 & 0,8 \\
\hline
\end{tabular}

A determinação da umidade foi realizada em laboratório, por meio de uma estufa, tomando como temperatura máxima o valor de $60{ }^{\circ} \mathrm{C}$. A umidade correspondente ao RSU da amostra 1 foi de $32,8 \%$ e da amostra 2 foi de $33,6 \%$, com média de $33,2 \%$. Para os ensaios realizados em abril de 2013, a umidade da amostra 1 foi de $20,6 \%$ e da amostra 2, 23,1\%, com média de 21,8\%. Santos (2012) realizou, na mesma célula experimental, em 2011, ensaios de umidade, obtendo um valor médio de $37,7 \%$. Pode-se observar que o teor de umidade diminui com o tempo, o que também foi verificado por Azevedo (2003).

O peso específico do RSU da célula experimental foi determinado em três momentos. Em 2011, foi determinado por meio dos dados do início da pesquisa, referindo-se aos resíduos despejados na célula experimental com dimensões de $14 \mathrm{~m} \times 14$ $\mathrm{m}$ de comprimento e $4 \mathrm{~m}$ de profundidade, indicando um peso específico de $7 \mathrm{kN} / \mathrm{m}^{3}$. $\mathrm{Em} 2012$, executou-se uma escavação, de $37 \mathrm{~cm} \times 20 \mathrm{~cm}$ e 
profundidade de aproximadamente $25 \mathrm{~cm}$, dentro da célula experimental; o peso específico obtido dessa forma foi de $17 \mathrm{kN} / \mathrm{m}^{3}$. Posteriormente, no ano de 2013, a partir da execução de uma escavação de $20 \mathrm{~cm} \times 20 \mathrm{~cm}$ e profundidade de $17 \mathrm{~cm}$, determinou-se um peso específico de $21,2 \mathrm{kN} / \mathrm{m}^{3}$.

Vale observar que os valores de peso específico obtidos em 2012 e 2013 são referentes ao resíduo compactado, diferentemente da obtenção de 2011.

Foram realizadas sondagens à percussão (SPT) na célula experimental e em um ponto de resíduo antigo, mas de mesmas características, localizado no interior do ASMOC e próximo da célula experimental.

A Figura 2 mostra o gráfico comparativo entre os resultados da sondagem realizada no resíduo antigo e na célula experimental.

O aterro antigo encerrou suas atividades há aproximadamente dez anos; por esse motivo, foi realizada a sondagem SPT para verificar a modificação de valores de índice de resistência com o tempo.

Como se observa na Figura 2, não houve mudança significativa do índice de resistência das sondagens realizadas na célula experimental e no aterro antigo.
$\mathrm{Na}$ sequência, foram determinadas as capacidades de carga do solo de cobertura e do maciço sanitário de resíduos utilizando formulações semiempíricas com base no índice de resistência. Essa determinação foi realizada tanto para o conjunto solo e resíduo da célula experimental quanto para o local do aterro onde se encontra o resíduo mais antigo.

As formulações utilizadas para as determinações da capacidade de carga foram as propostas por Meyerhof (1956) e De Mello (1967) e um método chamado "prático", válido para cálculos de sapatas em areia, sendo a pressão admissível expressa em $\mathrm{kg} / \mathrm{cm}^{2}$.

Os cálculos foram feitos considerando que a camada de cobertura tem o comportamento de solo granular e que o maciço de RSU apresenta comportamento crítico de um solo fino, o que equivale a considerar que a condição crítica do aterro, em termos de resistência, é a não drenada.

Vale ressaltar que a largura (B) da fundação utilizada no método de Meyerhof (1956) foi de $30 \mathrm{~cm}$, referente à placa de mesmo diâmetro.

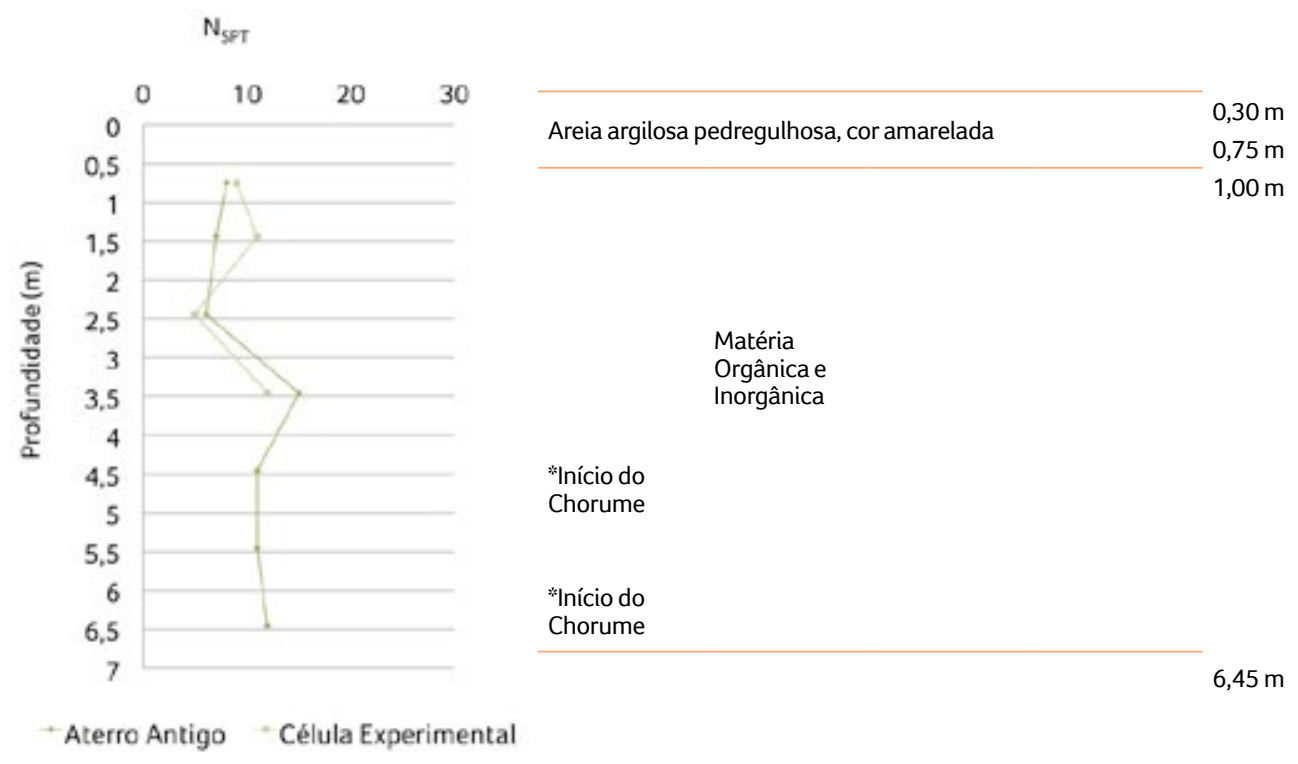

Figura 2 - Gráfico comparativo entre SPT do aterro antigo e célula experimental. 


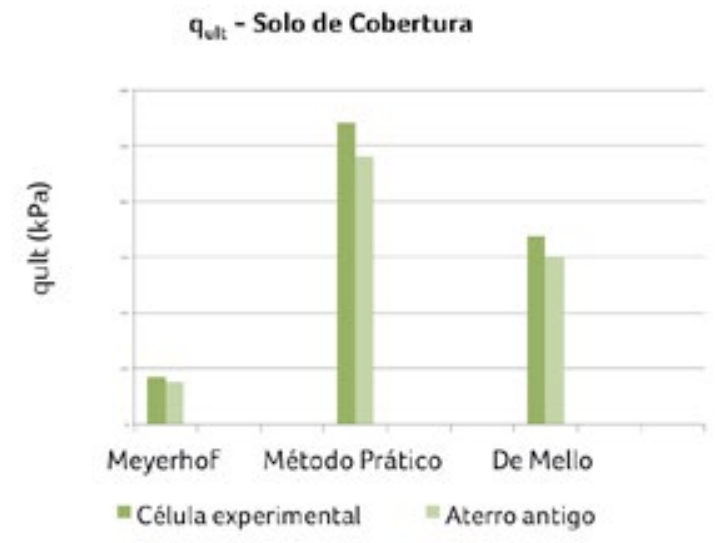

Figura 3 - Gráfico comparativo entre a tensão última $\left(\mathrm{q}_{\mathrm{ult}}\right)$ do solo de cobertura da célula experimental e do aterro antigo.

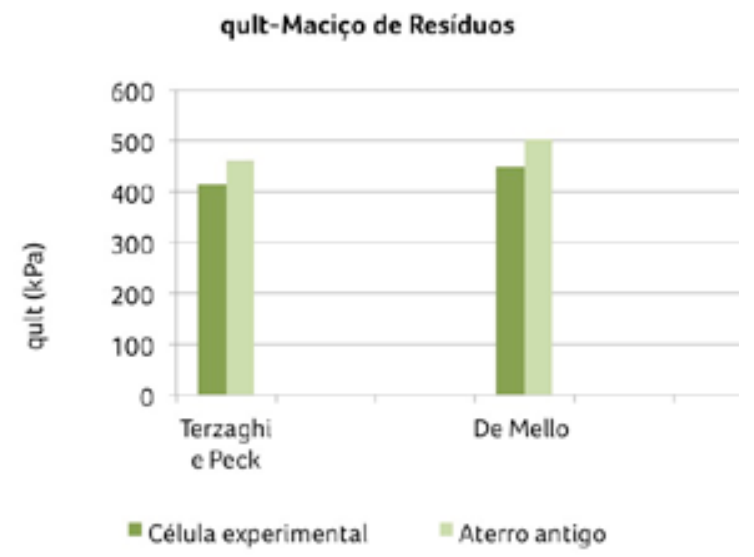

Figura 4 - Gráfico comparativo da capacidade de carga do maciço de RSU da célula experimental do aterro antigo a partir de sondagens à percussão.

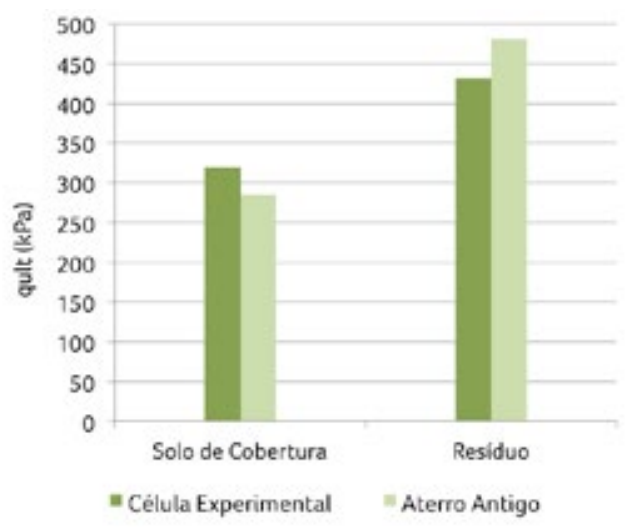

Figura 5 - Gráfico comparativo entre as médias das capacidades de carga dos solos de cobertura do maciço de RSU referente à célula experimental e ao aterro antigo.
A Figura 3 mostra um gráfico comparativo entre a capacidade de carga $\left(\mathrm{q}_{\mathrm{ult}}\right)$ do solo de cobertura da célula experimental e do aterro antigo.

A Figura 4 mostra a comparação da capacidade de carga do maciço de RSU da célula experimental do aterro antigo.

A capacidade de carga calculada no solo de cobertura e nos resíduos da célula experimental e do aterro antigo por meio de cada método para o respectivo aterro não variou muito, mostrando a similaridade dos métodos.

A maior capacidade de carga no solo de cobertura ocorre na célula experimental, provavelmente ocasionada pelo tipo de solo, e a maior capacidade de carga no maciço de resíduo ocorre no aterro antigo.

$\mathrm{Na}$ Figura 5, apresenta-se um gráfico comparativo entre as médias das capacidades de carga estimadas dos solos de cobertura do maciço de RSU tanto para a célula experimental quanto para o aterro antigo.

Por meio dos valores médios das tensões últimas, verificou-se que os métodos mais indicados para a análise no solo de cobertura e para o resíduo são, respectivamente, de De Mello (1967) e Terzaghi e Peck (1967), pois ambos diferem pouco da média.

Vale observar que as estimativas realizadas pelo método de De Mello (1967) apresentaram valor da capacidade de carga mais próximo da média para o solo de cobertura e para o maciço de RSU.

Foi realizado um ensaio de prova de carga direta na célula experimental utilizando uma placa de 30 $\mathrm{cm}$ de diâmetro e no aterro antigo utilizando placas de 30 e 50 cm de diâmetro.

Na Figura 6, mostra-se a curva pressão x recalque obtida com a realização do ensaio de prova de carga direta na célula experimental. 


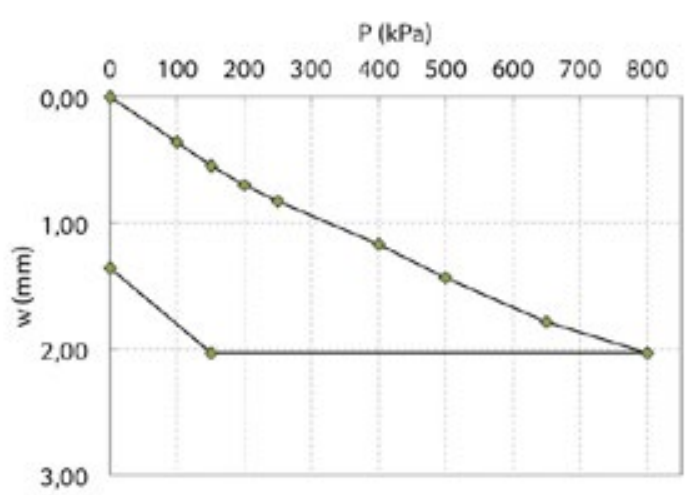

Figura 6 - Curva pressão x recalque referente à célula experimental utilizando placa de $30 \mathrm{~cm}$ de diâmetro.

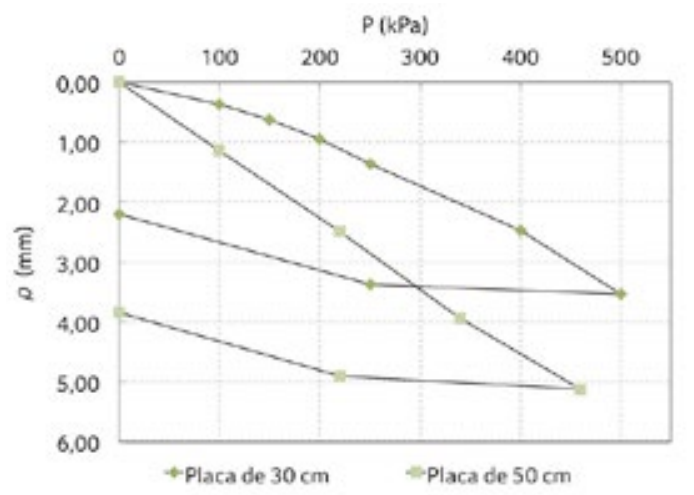

Figura 7 - Curvas pressão x recalque no aterro antigo utilizando placas de 30 e $50 \mathrm{~cm}$ de diâmetro.

$\mathrm{Na}$ Figura 7, são apresentadas as curvas pressão $x$ recalque no aterro antigo utilizando as placas de 30 e $50 \mathrm{~cm}$ de diâmetro.

Na sequência, foram determinadas as capacidades de carga tanto na célula experimental quanto no aterro antigo, a partir das provas de carga realizadas. Para isso, utilizaram-se os métodos da NBR 6122:2010 e de Van der Veen (1953).

Na Figura 8, apresenta-se a utilização do método da NBR 6122:2010 para determinação da capacidade de carga da célula experimental.

Como o método da NBR 6122:2010 não possibilitou a determinação da capacidade de carga da célula experimental, na sequência utilizou-se o método de Van der Veen (1953). No entanto, devido à elevada linearidade da curva pressão x recalque, que pode ser observada na Figura 6, a utilização

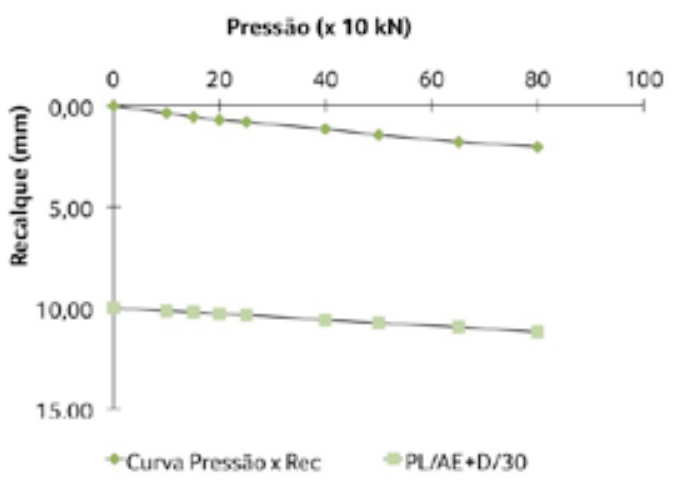

Figura 8 - Gráfico da capacidade de carga da célula experimental utilizando a NBR 6122:2010.

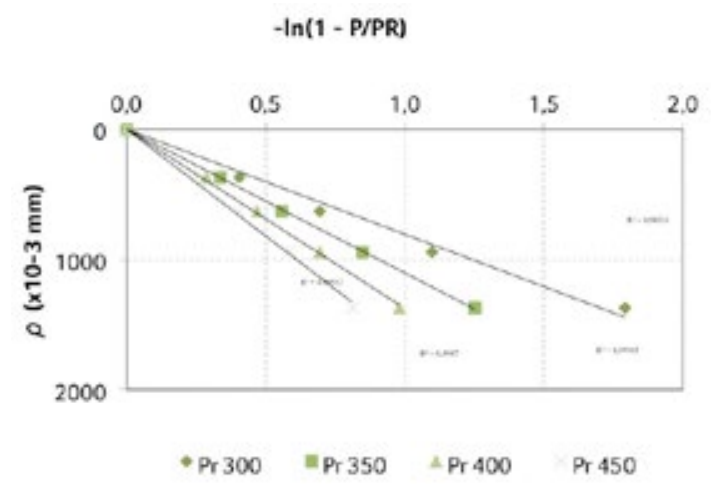

Figura 9 - Gráfico da capacidade de carga para placa de $30 \mathrm{~cm}$ no aterro antigo, utilizando o método de Van der Veen (1953).

desse método também não permitiu a extrapolação adequada da capacidade de carga.

Com a utilização do método de Van der Veen (1953), foi possível estimar apenas a capacidade de carga a partir do ensaio com a placa de $30 \mathrm{~cm}$, que foi realizado no aterro antigo (Figura 9).

Devido à impossibilidade da determinação da capacidade de carga na maioria das placas com a utilização do método de Van der Veen (1953), utilizaram-se alguns outros métodos disponíveis na literatura para a determinação da capacidade de carga (Quadro 1).

No Quadro 1, observa-se que a única placa em que foi possível a aplicação de alguns dos métodos selecionados para a determinação da capacidade de carga foi novamente a placa de $30 \mathrm{~cm}$ do aterro antigo, provavelmente por apresentar uma 
forma mais curva, o que não é observado nas outras placas. Verifica-se que, na placa de maior tamanho, ocorrem recalques maiores devido ao seu bulbo de tensões atingir maiores profundidades e, portanto, mobilizar uma espessura maior de solo.

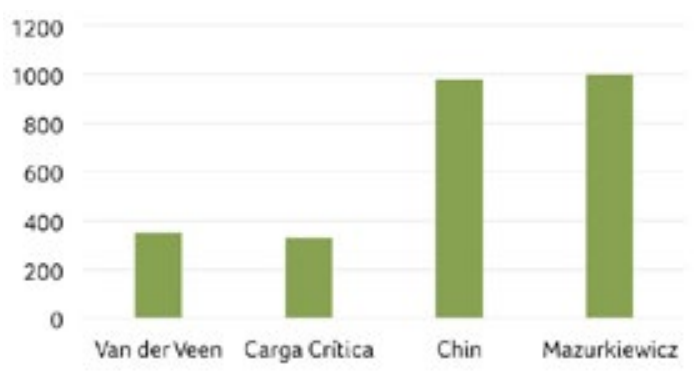

Figura 10 - Comparação entre as capacidades de carga do aterro antigo a partir da prova de carga com a placa de $30 \mathrm{~cm}$.

Quadro 1 - Métodos utilizados para determinação da capacidade de carga.

\begin{tabular}{|c|c|c|c|}
\hline \multirow{2}{*}{ Método } & Placa de $30 \mathrm{~cm}$ & $\begin{array}{c}\text { Placa de } 30 \\
\text { cm }\end{array}$ & $\begin{array}{c}\text { Placa de } 50 \\
\text { cm }\end{array}$ \\
\hline & $\begin{array}{c}\text { Célula } \\
\text { Experimental }\end{array}$ & $\begin{array}{l}\text { Aterro } \\
\text { Antigo }\end{array}$ & $\begin{array}{l}\text { Aterro } \\
\text { Antigo }\end{array}$ \\
\hline Davisson & Não aplicado & $\begin{array}{c}\text { Não } \\
\text { aplicado }\end{array}$ & Não aplicado \\
\hline Chin & Não aplicado & Aplicado & Não aplicado \\
\hline De Beer & Não aplicado & $\begin{array}{c}\text { Não } \\
\text { aplicado }\end{array}$ & Não aplicado \\
\hline $80 \%$ de Brinch & Não aplicado & $\begin{array}{c}\text { Não } \\
\text { aplicado }\end{array}$ & Não aplicado \\
\hline Mazurkiewicz & Não aplicado & Aplicado & Não aplicado \\
\hline Carga crítica & Não aplicado & Aplicado & Não aplicado \\
\hline Norma inglesa & Não aplicado & $\begin{array}{c}\text { Não } \\
\text { aplicado }\end{array}$ & Não aplicado \\
\hline
\end{tabular}

A Figura 10 mostra o resultado de todas as estimativas realizadas para a determinação da capacidade de carga do aterro antigo a partir da prova de carga com a placa de $30 \mathrm{~cm}$.

Observa-se que as estimativas da capacidade de carga para o aterro antigo a partir da prova de carga realizada com a placa de $30 \mathrm{~cm}$ apresentam valores bastante próximos quando realizadas a partir dos métodos de Van der Veen (1953) e da carga crítica. Na média, o valor estimado de capacidade de carga por esses métodos foi de $340 \mathrm{kPa}$. Por outro lado, as estimativas pelos métodos de Mazurkiewicz e Chin foram bastantes superiores e próximas. Nesse caso, a capacidade de carga média foi estimada em $1.007 \mathrm{kPa}$; dessa forma, a favor da segurança, adotou-se para a capacidade de carga do aterro antigo, a partir da prova de carga realizada com a placa de $30 \mathrm{~cm}$ de diâmetro, o valor de $340 \mathrm{kPa}$.

Por limitações executivas, não foram realizadas provas de carga direta propriamente nos resíduos dos aterros antigo e novo (célula experimental). Sendo assim, as avaliações e comparações da capacidade de carga apresentadas a partir das provas de carga se referem à solicitação dos aterros no topo do solo de cobertura. A partir das sondagens à percussão (SPT) realizadas, estimou-se que a capacidade de carga do maciço de RSU da célula experimental é de $432 \mathrm{kPa}$ e do solo de cobertura, de $320 \mathrm{kPa}$. Já para o aterro antigo, a capacidade de carga do maciço de RSU é de $480 \mathrm{kPa}$ e do solo de cobertura, de $285 \mathrm{kPa}$.

Comparando as capacidades de carga estimadas por meio de ensaios de prova de carga e sondagens à percussão, ambos realizados no solo de cobertura da célula experimental, observa-se que a capacidade de carga estimada por meio do ensaio de sondagem à percussão (SPT) foi de $320 \mathrm{kPa}$. A capacidade de carga do mesmo solo de cobertura estimada a partir do ensaio de prova de carga foi de $2.250 \mathrm{kPa}$. Verifica-se, assim, uma acentuada variação dos valores, que é atribuída à sucção devido à baixa umidade de compactação do solo, uma vez que a perfuração do solo foi realizada na sondagem à percussão (SPT) com a introdução de água para facilitar a escavação a trado. Além disso, as formas de aplicação de cargas nos dois ensaios são bastante diferentes, o que, obviamente, pode conduzir a resultados distintos.

Ademais, observa-se que a capacidade de carga estimada por meio da sondagem à percussão foi ligeiramente inferior à estimada por meio do ensaio de prova de carga (340 kPa). Ao contrário do que ocorreu na célula experimental, houve uma redução da capacidade de carga quando ela foi es- 
timada pela prova de carga. A esse resultado, atribuiu-se o aumento da umidade, pela ocorrência dos processos de biodegradação, que reduziram a sucção e, portanto, sua capacidade de carga.

\section{CONCLUSÕES}

A partir da realização desta pesquisa, foi possível estabelecer as seguintes conclusões:

- o solo utilizado na cobertura da célula experimental possui características adequadas para a execução do corpo de um aterro rodoviário;

- a composição gravimétrica dos RSUs provenientes da cidade de Fortaleza indica a predominância de matéria orgânica, confirmando as indicações apresentadas na literatura;

- os resultados das sondagens à percussão (SPT) realizadas nos resíduos do aterro antigo e da célula experimental não apresentaram variação significativa nos valores do índice de resistência $\left(\mathrm{N}_{\text {spt }}\right)$ das sondagens;

- as capacidades de carga estimadas com base no SPT, no solo de cobertura e no maciço de resíduo no aterro antigo e na célula experimental apresentaram valores semelhantes;

- a partir das provas de carga realizadas no solo de cobertura, verificou-se que as tensões externas aplicadas pela base das placas não atingiram de forma significativa o maciço de RSUs;

- a capacidade de carga estimada pelos ensaios de prova de carga e sondagem à percussão no solo de cobertura da célula experimental apresentou acentuada variação, devido à diferença de sucção no solo. Já no aterro antigo, a capacidade de carga estimada por meio da sondagem à percussão foi ligeiramente inferior, devido à menor diferença de sucção, consequência dos processos de biodegradação, determinados por meio de ensaios de prova de carga;

- preliminarmente, avalia-se que é possível utilizar a área do ASMOC como subleito de pequenas vias de acesso e área verde de parques recreativos dimensionados. Como suporte de pequenas edificações, a utilização será restrita a bases de pequenas dimensões, até $50 \mathrm{~cm}$, e desde que o solo de cobertura seja compactado com o controle geotécnico de compactação.

\section{REFERÊNCIAS}

AGUIAR, A. B O emprego do permeâmetro de guelph na determinação da permeabilidade do solo, de camadas de lixo e sua cobertura.2001. 67p. Dissertação (Mestrado)- Engenharia Civil, Universidade Federal do Rio de Janeiro, Rio de Janeiro,2001.

AZEVEDO, R. F.; CARVALHO, A. R.; AZEVEDO, I. C. D.; MARQQUES, E. A. G. Variação com a idade de características dos resíduos do aterro sanitário de Santo André, São Paulo. In: CONGRESSO BRASILEIRO DE GEOTECNIA AMBIENTAL, 5, 2003, Porto Alegre, 5. CD-ROM.

BOSCOV, M. E. G. Geotecnia ambiental. São Paulo: Oficina de Textos, 2008. 248p.

CARNEIRO, A.A. Estudo da capacidade de carga de uma célula experimental de resíduos sólidos urbanos com base em ensaios de laboratório e campo. Fortaleza. 2013.139 p. Dissertação (Mestrado em Geotecnia) - Centro de Tecnologia, Departamento de Engenharia Hidráulica e Ambiental, Universidade Federal do Ceará, Fortaleza, 2013.

CARVALHO, M.F. Comportamento geotécnico de resíduos sólidos urbanos. São Carlos. 1999. 300 p. Tese (Doutorado em Geotecnia) Escola de Engenharia de São Carlos, Universidade de São Paulo, São Carlos, 1999.

DEPARTAMENTO NACIONAL DE INFRAESTRUTURA DE TRANSPORTES - DNIT. DNIT 108/09: Terraplanagem-Aterros-Especificação de Serviço. Rio de Janeiro, 2009.

GONZALEZ, J. H. P. Comportamiento geotecnico de vertederos controlados de resíduos solidos urbanos. 1995. 587p. Tesis (Doctoral) - Escuela técnica Superior de Ingenieros de Caminos, Canales y Puertos. Universidade de Cantabria, Santander, Espana, 1995.

KNOCHENMUS, G.; WOJNAROWICZ, M.; VAN IMPE, W.F. Stability of municipal solid wastes. In: INTERNATIONAL CONGRESS ON ENVIRONMENTAL GEOTECHNICS, 3., 1998, Lisbon, Portugal, v.3, p.977-1000.

MACHADO, S. L.; CARVALHO, M. F.; DOURADO, K.A.; ROCHA, M.B.; LOPES, C. L. Estudo da compressibilidade de resíduos sólidos urbanos da região metropolitana de Salvador/ BA. In: CONGRESSO BRASILEIRO DE ENGENHARIA SANITÁRIA E AMBIENTAL, 23., 2005, Campo Grande.

SANTOS, G. O. Avaliação do cultivo de gramíneas na superfície de aterro sanitário, com ênfase para a redução da emissão de metano e dióxido de carbono para a atmosfera. 2012. 313p. Tese (Doutorado) Universidade Federal do Ceará, Fortaleza, 2012.

TERZAGHI, K.; PECK, R. B. Soil mechanics in engineering practice. New York: John Wiley and Sons, v.2, 1967. 